\title{
DL DIGITAL
}

\section{Proceedings of the 20th ACM international conference on Information and knowledge management}

Editors: Bettina Berendt

Arjen de Vries

Wenfei Fan

Craig Macdonald University of Glasgow, UK

Iadh Ounis

University of Glasgow, UK

Ian Ruthven

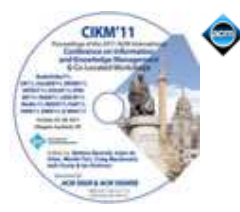

2011 Proceeding

\section{Bibliometrics}

Downloads (6 Weeks): 8,501

Downloads (12 Months): 11,070

Citation Count: 0
Tools and Resources

(4) TOC Service:

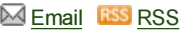

Save to Binder

Export Formats:

BibTeX EndNote ACM Ref

Hit Upcoming Conference: $\underline{\text { CIKM'12 }}$

Share:

Publication of:

- Conference

CIKM ' 11 International Conference on Information and Knowledge Management

Glasgow, United Kingdom - October 24 - 28, 2011

ACM New York, NY, USA ๑2011

Feedback | Switch to single page view (no tabs)

Abstract Source Materials Authors References Cited By Index Terms Publication Reviews Comments Table of Contents

On behalf of the organizing committee, it is our great pleasure to welcome you to the 20th ACM Conference on Information and Knowledge Management in Glasgow!

Since its inception, the CIKM conference has provided a unique international forum for the presentation, discussion and dissemination of research findings in data management, information retrieval and knowledge management. The purpose of the conference is to identify challenging problems facing the development of future knowledge and information systems and to shape future research directions through the publication of high quality, applied and theoretical research findings. The conference has been a leading forum in which experts from academic, industry and the public sector gather to exchange ideas, research achievements and technical developments in multidisciplinary research areas.

CIKM is one of the world's most recognized conferences in the field. This year CIKM received 918 full paper submissions, 220 poster submissions, and 56 demonstration submissions. This is a great demonstration of the lively research areas that contribute to the CIKM area. In addition, CIKM 2011 will host 10 tutorials from leading researchers, 15 workshops on cutting-edge areas of research, a panel session on Social and Collaborative Search and a dedicated Industry Day featuring leading industrial practitioners. We are grateful to all authors who chose to submit their research to CIKM 2011 and are very excited by the final program.

CIKM values interdisciplinary research and we are proud to present three keynote speakers, Professor Justin Zobel, Professor Maurizio Lenzerini and Professor David Karger, all of whom will give presentations that cross discipline boundaries. 
The ACM Digital Library is published by the Association for Computing Machinery. Copyright $\odot 2012$ ACM, Inc. Terms of Usage Privacy Policy Code of Ethics Contact Us

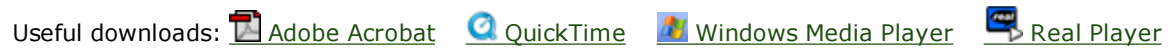

